\title{
The Influence of RMB Real Exchange Rate on the Technical Structure of Sino-US Export Trade Products
}

\author{
Yuliang Lu \\ College of Economics, Jinan University, Guangzhou, China \\ Email: yulianglu1234@163.com
}

How to cite this paper: Lu, Y.L. (2018) The Influence of RMB Real Exchange Rate on the Technical Structure of Sino-US Export Trade Products. American Journal of Industrial and Business Management, 8, 1261-1276.

https://doi.org/10.4236/ajibm.2018.85086

Received: April 28, 2018

Accepted: May 18, 2018

Published: May 21, 2018

Copyright $\odot 2018$ by author and Scientific Research Publishing Inc. This work is licensed under the Creative Commons Attribution International License (CC BY 4.0).

http://creativecommons.org/licenses/by/4.0/

\begin{abstract}
Based on the classification of HS (Harmonized Commodity Description and Coding System), and according to the method of Lall (2000) [1], Sino-US trade products are divided into five categories, namely primary products, resource-intensive products, low technology products, medium technical products and high-tech products. Based on the data from the first quarter of 2005 to the fourth quarter of 2017, the influence of bilateral real exchange rate on the structure of Sino-US export trade was studied by using VAR model in this paper. The empirical results show that there is a strong granger causality between Sino-US bilateral real exchange rate and Sino-US export trade product structure, the former being the latter's granger reason; in the short term, the appreciation (devaluation) of the real exchange rate between China and the US is conducive (inconducive) to an improvement in the trade structure, which has long been detrimental (beneficial) to the improvement of the trade structure. In general, the appreciation of RMB is unfavorable to the improvement of the technical structure of Sino-US export trade. Variance decomposition shows that Sino-US bilateral real exchange rate has a great contribution to the technical structure of Sino-US export trade.
\end{abstract}

\section{Keywords}

RMB Real Exchange Rate, Technical Structure, Improvement, VAR Model

\section{Introduction}

Under the background of economic globalization and the gradual opening of international market, the sustained and steady development of foreign trade of a country is the key factor to achieve economic growth and external equilibrium. 
The exchange rate, as a relative price between countries and macro-policy variables, plays an important role in the internal and external equilibrium of a country's economy and the stable development of its economy, which is the key factor influencing the development of foreign economy and trade.

Since 1994, China has implemented “a single, managed floating exchange rate system based on market supply and demand", which has been the combination of official quotations and adjustment prices for the RMB exchange rate, and the US dollar against the renminbi has been lowered to 8.70, according to the People's Bank of China, and then begins to appreciate slowly. Between 1994 and 2005, China's exchange rate system gradually evolved into a single dollar exchange rate system, to maintain stability. From July 21, 2005, the renminbi was no longer only pegged to dollar, but instead "a more flexible floating exchange rate system based on market supply and demand, and was pegged to a basket of currencies", and the renminbi against the dollar revalued by $2 \%$ percent to 8.11 yuan to $\$ 1$ at one time.

The renminbi is appreciating against the dollar over the next three years, rising by about $6 \%$ a year. By September 2008, the exchange rate between the renminbi and the dollar had risen to 6.83 yuan against 1 dollar. Affected by the financial crisis, our country then suspended the reference to a basket of currencies exchange rate system, again pegged the renminbi exchange rate with the U.S. dollar, basically kept at 6.82 yuan to 1 dollars. Two years later, the world economy recovered slowly, and the People's Bank of China officially announced on June 19, 2010 that it would continue to push for reform of the renminbi's exchange rate regime in order to enhance its exchange rate flexibility and floating space. The appreciation of the renminbi increased in 2010-2012, on December 21,2012 , the renminbi's median exchange rate was about 6.2285. By December 31,2014 , the renminbi's floating range had widened to $2 \%$, and the renminbi's median exchange rate was 6.20. Between 2014 and 2015, the renminbi fluctuated against the dollar, but overall the renminbi tended to depreciate. In 2016, devaluation widened further, by December 30, the renminbi's median exchange rate against the dollar was 6.9370 , down about $6.39 \%$ compared with the rate on December 31, 2015. In 2017, the renminbi entered a period of slow appreciation, the average of median exchange rate of RMB lowered from 6.8918 in January 2017 to average of 6.5942 in December 2017, appreciating about 4.51\%. (Note: the data of exchange rate all come from the People's Bank of China.)

At the same time, despite the slow rise in 2005 and the sharp appreciation after the exchange change, China's export trade with the United States is not in line with expectations. Since 21st century, China's trade surplus with the United States has continued to rise. According to the Statistics of General Administration of Customs, P. R. China in 2006, China's U.S. trade surplus against the United States is 1442.63 billion U.S. dollars, accounting for $81.27 \%$ of China's total foreign trade surplus. According to the Statistics of General Administration of Customs, P. R. China in 2017, China-US trade surplus was as highly up to 2758.12 billion U.S. dollars, rose nearly twice. While the Sino-US trade surplus 
accounted for China's total trade surplus has fallen to $65.44 \%$, but still high. As to the Exports, China's exports to the United States have been expanding from 2034.72 billion U.S. dollars in 2006 to 4297.55 billion U.S. dollars in 2017 of, increasing by more than twice. The proportion of exports to the US has fallen from $21.00 \%$ in 2006 to $18.99 \%$ in 2017 , but still stubbornly high.

Under the background of the RMB appreciation, and the increasingly growing of Sino-US trade surplus and the amount of exports, what happened to the Sino-US export trade product structure. Under the historical background of RMB internationalization, supply side reform and trade structure optimization, the United States, as the largest trading country of China, studies about the relationship between exchange rate fluctuation and the technical structure of Sino-US export trade products, has certain practical significance and instructive significance. Because the trading between countries is similar to some extent, the studies of the relationship between China and America, the largest trading country of China, can set guidelines for China to take some measures to deal with the trade relationship with other countries. Besides, the study can also demonstrate the trade situation and exchange rate fluctuation, thus helping China to reflect on the effect of the exchange rate on different industries and products, which may be helpful for the making and implementation of some relevant policy.

\section{Literature Review}

In theoretical research, Barry J. Eichengreen (1983) [2] believed that changes in exchange rates would affect the price of a country's terms of trade, which in return would change the allocation of resources and affect the trade structure. Based on the micro-enterprises, Jeannette Capel (1994) [3] held the opinion that changes of a country's exchange rate would lead to the relative changes in production costs, and multinational companies would change the proportion of input elements for the goal of maximizing profits. In this condition, the different exports products with different inputs would suffer from different degrees of impact, and finally a country's foreign trade products structure changed. Obstfeld and Rogoff (1996) [4] felt that a stronger currency would increase the price of both technology-intensive and labor-intensive products in the international market, but the price of technology-intensive products would rise less than the increase in labor-intensive products. Hence the international competitiveness of technology-intensive products would be enhanced relatively and its relative scale would expand, thus promoting the upgrading of trade product structure of export trade.

In empirical research, based on Japan's data from 1978 to 1996, Janice Boucher Breuer and Leianne A. clements (2003) [5] studied the yen exchange rate and Japan's import and export trade, and found that exports were more sensitive to exchange rate movements than imported goods, The impact of exchange rate changes on the structure of trade products can be negligible. Mohsen Bahmani-oskooee and Scott W. hegerty (2009) [6] studied the effect of the devaluation 
of the yen on trade between Japan and the US from short and long term by using Cointegration test method, and the research results showed that one third of the trade industry would be improved due to the depreciation of the yen in the long, which differs from industry to industry. Mario, Sebastian and Gabriel (2013) [7] used data of 11 countries from 1962 to 2008, studying the impact of exchange rate changes on the technical intensity of export-trade product structures. They believed that a higher exchange rate will make the division of labor of export trade higher, in this division of labor, export trade product technology intensity will be upgraded, and ultimately promote a country's export trade product structure improvement.

Under the background of RMB appreciation, domestic scholars have done a lot of research on the relationship between RMB exchange rate fluctuation and export trade structure, mainly focusing on the empirical research. Conclusions can be divided into three categories:

Most scholars' empirical research results support the view that RMB appreciation is beneficial to the improvement of China's export trade structure. Zengzheng and Zhang Yabin (2007) [8] divided the export trade products into capital-intensive and labor-intensive products, calculating the exchange rate elasticity, and found that the export of labor-intensive products was more affected by the exchange rate impact because of the different intermediate inputs. The further analysis showed that the appreciation of RMB exchange rate can promote the development of capital-intensive industries and optimize the structure of export products, but the improvement of export trade product structure has little effect on the appreciation of RMB exchange rate. Wang Yuwen (2009) [9] used ARDL-ECM model and Pesaran boundary test method, defined the export structure as the ratio of resource-intensive and labor-intensive product exports to the export of capital technology intensive products respectively, and found that since the 2005's exchange rate reform, the appreciation of RMB has had obvious and enormous effect on the upgrading of export structure. In order to eliminate the interaction between variables, Jin Guohua (2010) [10] studied the changes of RMB exchange rate and the structure of export trade products by constructing VAR model. The results show that the appreciation of RMB will cause the export scale of primary products and industrial manufactures to change in different degree, which leads to the different change of export proportion and thus promote the improvement of the trade structure. Based on the standard International Trade Classification (SITC), Xiao Quanxi and Liao Wenxiu (2012) [11], Yu Juanjuan and Linling (2013) [12], studied the exchange rate elasticity of the export amounts of large categories of encoded goods, the results show that the negative impact of RMB revaluation on capital-intensive products is less than the negative impact on the export of labor and resource-intensive products, which is conducive to the improvement of export structure. In order to solve the problem of synthetic fallacy of the wide range of commodity classification, Zhang Huiqing (2015) [13] used the export data of HS six digits code of the 20 main export markets between 2005 and 2012 and based on the two-stage 
estimation method combining the sample selection model with the Hausman-taylor AR (1) regression, calculated the exchange rate elasticity from the technical product level. The results show that the appreciation of the RMB increases the proportion of the export scale of High-tech products in the total export scale, but the impact on the Medium-tech products is greater than the resource-intensive products, therefore, the improvement of the trade structure is only local.

However, some scholars have found that the appreciation of RMB has no significant effect on China's export trade structure. Madan and Xu Shaoqiang (2005) [14] discovered that the upgrading of export commodity structure would affect exchange rate changes, but exchange rate changes would not affect the structure of export commodities. By using causality test and error correction model, Ou Yuanming and Wang Shaoping (2005) [15] held that the real effective exchange rate has no causal relationship with the export of Chinese domestic enterprises, and the change of RMB exchange rate has no significant influence on the trade structure of China. Deng Shuilan and Wen Yizhong (2008) [16] said that short-term exchange rate movements had little impact on trade restructuring. Huang Wanyang and Wang Weiguo (2010) [17] found that the appreciation of the renminbi had no significant effect on the structure of export products.

Another part of scholars' research shows that the appreciation of RMB will inhibit the improvement of China's export trade structure. Li Hongbin and Ma Hong, Xiong Yanyan and Xuyuan (2011) [18] used the annual panel data of the micro-enterprise to measure the RMB exchange rate elasticity from the angle of capital density and industry technical level, the results show that labor-intensive industry and low technology industry are less impacted by RMB appreciation, while the High-tech industry is impacted greatly. Maybe it's because of the fact that the first two kinds of products' comparative advantage is more obvious, demand price elasticity is low, and high-tech industry's comparative advantage is weaker. Deng Xiaohua and Li Zhan feng (2014) [19] used VAR model to analyse the two kinds of products of industrial manufactures and primary products, and held that the real exchange rate appreciation is unfavorable to the improvement of our country's export trade product structure, and the depreciation of real exchange rate will rather improve the export trade product structure.

Overall, domestic and foreign studies have verified the relativity between exchange rate and trade structure both theoretically and empirically, and research about the influence of exchange rate on China's export trade structure was mainly from country angle. The relationship between exchange rate and Sino-US trade was mainly focused on the study of exchange rate and Sino-US trading volume, with few studies on correlation of exchange rate and the Sino-US export trade structure. Although the US is not China's biggest exporter, it is China's largest export country. Therefore, studying the impact of exchange rate changes on the structure of Sino-US exports will not only provide a more convincing play on the relevance of exchange rates and trade structures, but also is possible 
to explore the difference between bilateral exchange rate changes in the Chinese and American export trade product structure.

\section{Model Setting and Data Selection}

\subsection{The Setting of Empirical Model}

In this paper, a vector autoregressive (VAR) model is selected for econometric analysis, in 1980, Christopher Sims based on statistical characteristics of data and proposed VAR model, which constructs the model by using each endogenous variable as a function of the hysteresis value of all endogenous variables in the system. Then the autoregressive model of single variable is extended to the "vector" autoregressive model composed of multivariate time series variables. At the same time, exogenous variables can be introduced into the model, and the general equation expressions of the var model with delay P-order are as follows:

$$
y_{t}=c+M_{1} y_{t-1}+M_{2} y_{t-2}+\cdots+M_{p} y_{t-p}+H x_{t}+\partial_{t}, t=1,2,3, \cdots, T
$$

In the model, $y_{t}$ is a column vector of m-dimensional endogenous variables, the $x_{t}$ is an $\mathrm{n}$-dimensional exogenous variable column vector, and $p$ is the delay order of the variables, and $T$ is the number of samples. $\mathrm{m}^{*} \mathrm{~m}$ dimensional matrix $M_{1}, \cdots, M_{p}$ and the $\mathrm{m}^{\star} \mathrm{n}$ dimensional matrix $H$ is the coefficient matrix to be estimated, $c$ is the m-dimensional constant sequence vector, an $\partial_{t}$ is $\mathrm{m}$-dimensional perturbed column vector. VAR model is a kind of unstructured multiple equation model without prior constraints, but the form is flexible and the parameters are easy to estimate. The model can be used to estimate the general time series data, and then reveal the interaction between endogenous variables in the model. Therefore, this paper uses this model to analyze the relationships between real exchange rate fluctuation of RMB against the dollar and the Sino-US export trade products' structure.

In this paper, we use RE and ES as endogenous variables, GDPG, FTG and FAG as exogenous variables to set the VAR model, the matrix expressions are as follows:

$$
\begin{aligned}
\left(\begin{array}{l}
E S_{i, t} \\
R E_{t}
\end{array}\right)= & \left(\begin{array}{l}
c_{0} \\
c_{0}
\end{array}\right)+\left(\begin{array}{ll}
a_{11}^{1} & a_{12}^{1} \\
a_{21}^{1} & a_{22}^{1}
\end{array}\right)\left(\begin{array}{c}
E S_{i, t-1} \\
R E_{t-1}
\end{array}\right)+\cdots+\left(\begin{array}{ll}
a_{11}^{p} & a_{12}^{p} \\
a_{21}^{p} & a_{22}^{p}
\end{array}\right)\left(\begin{array}{c}
E S_{i, t-p} \\
R E_{t-p}
\end{array}\right) \\
& +\left(\begin{array}{lll}
b_{11} & b_{12} & b_{13} \\
b_{21} & b_{22} & b_{23}
\end{array}\right)\left(\begin{array}{c}
G D P G_{t} \\
F T G_{t} \\
F A G t
\end{array}\right)+\left(\begin{array}{l}
\partial_{1} \\
\partial_{2}
\end{array}\right)
\end{aligned}
$$

Note: the explanation of the endogenous variables and exogenous variables are shown in the following context "3.2 Selection of Variables and Data".

\subsection{Selection of Variables and Data}

This part will empirically analyze the relationship between China's export product structure and the real exchange rate of RMB against US dollar. Considering that the RMB exchange rate is more market-oriented after 2005, and for the rationality and accuracy of the thesis research, this paper selects the data from the 
first quarter of 2006 to the fourth quarter of 2017 for analysis and research, all the data are from the relevant statistical website (detailed below) and after the $\mathrm{X} 12$ seasonal adjustment. The following is a detailed description of the variables and data selected in the paper:

\section{The Empirical Analysis}

\subsection{ADF Test}

The theory shows that the pseudo regression is easy to be generated when the Non-stationary time series data is returned directly by the row least square method (OLS), so we need to test the data smoothly. This paper uses ADF to test the unit root of all variables, and the estimated results obtained by Eviews 7.2 Software are shown in Table 1.

The stationary test results for all variables can be seen from Table 2, and the default SIC guidelines are used for all data lag periods. The above results show that the original data is stable under the $5 \%$ significant level, and can be directly analyzed by VAR model.

\subsection{Selection of the Lagging Order}

In the analysis of VAR model, it is very important to choose the delay order of the variables and the difference of the lagging order leads to the great differences of the estimation results. Large lagging order can better reflect the dynamic relationship between variables, it will reduce the degree of freedom in the system and not conducive to analysis if the order is too large. Therefore, it is necessary to analyze the relationship accurately between the variables in the model without losing its own degree by choosing the appropriate lagging order. The results of the test by Eviews 7.2 based on the preliminary VAR model are shown in Table 3 .

According to Table 3, we can see the estimation results of the LOGL, LR, FPE, AIC, SC, and HQ of the initial VAR model for the 0 to 4-order lagging order. In general, there are two methods which can be used to test the optimal lagging order for the VAR model that is AIC information criterion, SC criterion and LR test. SC Criterion and AIC Information criterion are commonly used in literatures. From Table 3, all criteria show that the 2-order lag should be selected, so the VAR model in this paper is analyzed by 2-order lag.

Table 1. The results of ADF test.

\begin{tabular}{ccccc}
\hline Variables & Value of ADF test & Form of test $(c, t, k)$ & Critical value & Conclusion \\
\hline RE & -3.05239 & $(c, 0,1)$ & -2.926622 & Stationary \\
ES & -3.28066 & $(c, 0,0)$ & -2.925169 & Stationary \\
GDPG & -4.41518 & $(c, 0,0)$ & -2.925169 & Stationary \\
FTG & -3.49674 & $(0,0,4)$ & -1.948686 & Stationary \\
FAG & -5.35903 & $(\mathrm{c}, \mathrm{t}, 0)$ & -3.508508 & Stationary \\
\hline
\end{tabular}


Table 2. Description of the endogenous variables and exogenous variables.

\begin{tabular}{|c|c|c|}
\hline $\begin{array}{l}\text { Endogenous } \\
\text { variables }\end{array}$ & Meaning and explanation & Data source and processing \\
\hline RE & $\begin{array}{l}\text { RErepresents the real exchange rate of RMB against the United } \\
\text { States dollar, because nominal exchange rate does not eliminate the } \\
\text { price factor between the two countries and can't reflect the } \\
\text { truerelationship between exchange rate and trade structure, } \\
\text { this paper uses the Chinese and American Consumer Price } \\
\text { index to calculate the bilateral real exchange rate } \\
\text { to eliminate the impact of inflation on the exchange rate. }\end{array}$ & $\begin{array}{l}\text { The Sino-US bilateral nominal exchange rate data } \\
\text { comes from the People's Bank of China website, } \\
\text { through the monthly final exchange rate data to get } \\
\text { the quarterly nominal exchange rate. U.S. monthly } \\
\text { CPI data comes from the U.S. Labor Department's } \\
\text { monthly month-on-month CPI, after the X12 seasonal } \\
\text { adjustment and then take the monthly average of the } \\
\text { U.S. quarterly CPI. China's monthly month-on-month } \\
\text { CPI data comes from the National Bureau of Statistics, } \\
\text { processed by the same approach as the United States. } \\
\text { Based on the first quarter of 2006, the CPI benchmark } \\
\text { index of the United States and China are calculated, } \\
\text { and finally calculate the Sino-US bilateral real } \\
\text { exchange rate, which is expressed in RE. }\end{array}$ \\
\hline ES & $\begin{array}{l}\text { ESrepresentsChina's export Trade product technology structure, } \\
\text { Referring to the classification method of Lall (2000), based on HS } \\
\text { classification criteria, this paper divides the export products of the } \\
\text { United States into primary products, resource-intensive products, } \\
\text { low technology products, medium and high technology products } \\
\text { according to the technical value added. The technical structure of } \\
\text { China's exports to the United States is represented by the medium } \\
\text { and high technology products' amount of China's total amount of } \\
\text { exports to the United States, which is expressed in ES. }\end{array}$ & $\begin{array}{l}\text { The HS classified export data are from the } \\
\text { People's Republic of China General } \\
\text { Administration website. }\end{array}$ \\
\hline $\begin{array}{l}\text { Exogenous } \\
\text { variables }\end{array}$ & Meaning and explanation. & Data source and processing. \\
\hline GDPG & $\begin{array}{l}\text { GDPGrepresentsUS real GDP growth rate, the real GDP growth rate } \\
\text { in the United States is to explain its changes to the export structure } \\
\text { from the perspective of American demand for China's export trade } \\
\text { products. The real GDP growth rate of US represents the change rate } \\
\text { of foreign income, and the change of foreign income will affect the } \\
\text { change of American demand for China's export products. While the } \\
\text { foreign consumers have different income elasticity to the demand of } \\
\text { China's export trade products. Therefore, the change of income will } \\
\text { cause the change of demand. The export scale of China's export } \\
\text { products has different degrees of impact on the export of our } \\
\text { products structure, but the impact of the change of export structure } \\
\text { and exchange ratechange on foreign GDP growth rate is small, so in } \\
\text { this paper, the real GDP growth rate is an exogenous variable. }\end{array}$ & $\begin{array}{l}\text { The data of America's quarterly real GDP come } \\
\text { from the U.S. Bureau of Economic, } \\
\text { which was seasonally adjusted by X12 to } \\
\text { calculate the real GDP growth rate } \\
\text { for the quarter, expressed in GDPG. }\end{array}$ \\
\hline FTG & $\begin{array}{l}\text { FTGrepresentsthe proportion of the FDI to GDP, the proportion of } \\
\text { the FDI to GDP is to explain its changes to the structure of export } \\
\text { trade from the point of supply of export trade, because China's FDI } \\
\text { enterprises have a very important role in China's export. The } \\
\text { movement of international capital is often accompanied by the } \\
\text { movement of technology, management experience and so on, } \\
\text { and the advanced technology will bring the change of product } \\
\text { technology content, and finally promote the change of export trade } \\
\text { structure. the proportion of the FDI to GDP represents the role of } \\
\text { foreign capital in China's economy, to explain the impact of source } \\
\text { of factors on export structure. The existing literatures regarded it } \\
\text { as an endogenous variable when using VAR model to deal with the } \\
\text { research, but in this paper we argue that FDI is a policy variable } \\
\text { to a large extent, which is influenced by the factors of national policy. } \\
\text { The impact of export structure on FDI is smaller, so the proportion } \\
\text { of FDI to GDP is analyzed as exogenous variable. }\end{array}$ & $\begin{array}{l}\text { China's GDP data are from the National Bureau } \\
\text { of Statistics, and FDI are the actual amount } \\
\text { of foreign investment, coming from the } \\
\text { Ministry of Commerce. }\end{array}$ \\
\hline
\end{tabular}


FAGrepresentsGrowth rate of fixed asset investment completion, the growth rate of fixed assets investment is to measure the change

FAG of domestic investment level, the change of domestic investment level will have some influence on China's foreign export trade structure, this paper analyzes it as exogenous variable in the model.
The quarterly data of the fixed assets investment completion and the quarterly data of the real estate development investment are all from the National Bureau of Statistics. Considering that the investment in real estate development will not enter into the trade products industry, the real estate development investment completion amount is deducted from the completion amount of the fixed assets investment as the fixed assets investment. Using the quarterly fixed asset Investment price index (from the National Bureau of Statistics) to eliminate price factors to obtain the quarterly data of actual fixed asset investment completion, and then adjusts seasonally with X12 method, finally get the growth rate of real fixed assets investment in the quarter.

Table 3. Test results of lagging order.

\begin{tabular}{ccccccc}
\hline Lag & Log L & LR & FPE & AIC & SC & HQ \\
\hline 0 & 132.4119 & NA & $1.20 \mathrm{E}-05$ & -5.655086 & -5.330688 & -5.534784 \\
1 & 209.8682 & 133.7881 & $4.27 \mathrm{E}-07$ & -8.994009 & -8.507411 & -8.813555 \\
2 & 217.8636 & $13.08346^{*}$ & $3.58 \mathrm{e}-07^{*}$ & $-9.175620^{*}$ & $-8.526824^{*}$ & $-8.935015^{*}$ \\
3 & 219.1863 & 2.044145 & $4.07 \mathrm{E}-07$ & -9.053924 & -8.242928 & -8.753167 \\
4 & 222.0738 & 4.199969 & $4.34 \mathrm{E}-07$ & -9.003354 & -8.03016 & -8.642447 \\
\hline
\end{tabular}

Note: ${ }^{\star}$ Represents the lagging order of the selected from each column criterion.

\subsection{Stability Test}

Although the optimal lag order of the model has been determined, it does not ensure that the relevant estimation results are effective. It requires that the model is stable, and the condition of the model stability is the reciprocal of the modulus of all the roots are in the unit circle. If the reciprocal of four roots exists outside the unit circle, then the model may not be stable, and the model's impulse response and variance decomposition analysis may be ineffective. The unit root diagram of the model is shown in Figure 1.

According to Figure 1, the reciprocal of the model's four roots is in the unit circle, so the model is stable.

\subsection{Granger Causality Test}

The causal relationship tested by Granger causality test is not a general cause and result, and its essence is whether a variable's hysteresis can be introduced into the equation of another variable for interpretation and analysis. If the lag term of a variable has an effect on another variable, it is said that there is a causal relationship between them. In this paper, we did the Granger causality test in the 2-order VAR model, and the results are shown in Figure 2.

According to Figure 2, under the 1\% significant level condition, the Sino-US bilateral real exchange rate is the Granger reason of the Sino-US export trade 
Inverse Roots of AR Characteristic Polynomial

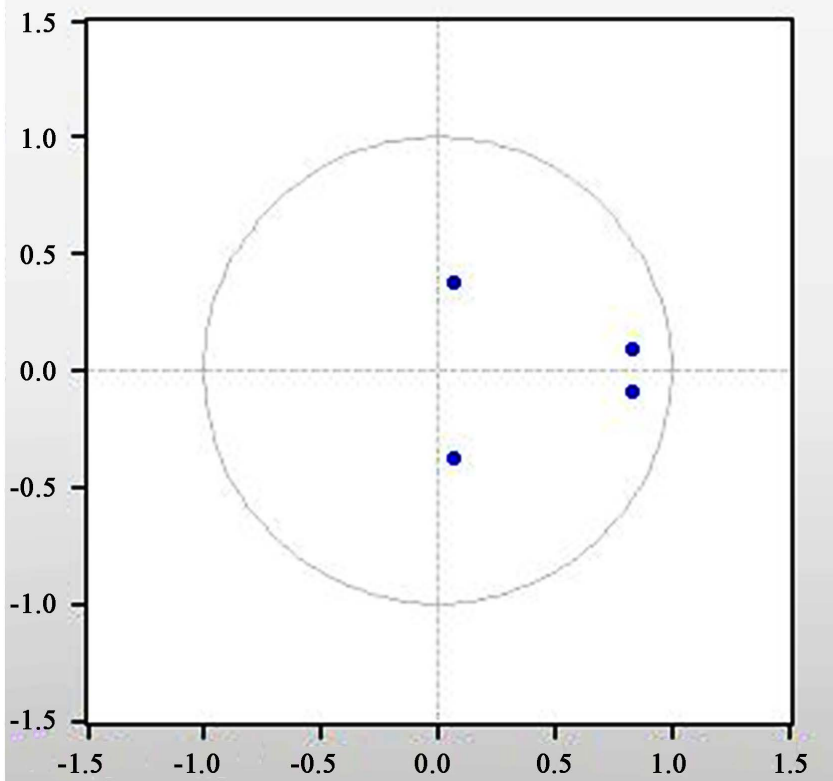

Figure 1. Stability test or the VAR model.

VAR Granger Causality/Block Exogeneity Wald Tests

Date: 04/14/18 Time: 18:55

Sample: 2006Q1 2017Q4

Included observations: 46

Dependent variable: $\mathrm{RE}$

\begin{tabular}{cccc}
\hline \hline Excluded & Chi-sq & df & Prob. \\
\hline \hline ES & 1.614087 & 2 & 0.4462 \\
\hline \hline All & 1.614087 & 2 & 0.4462 \\
\hline \hline
\end{tabular}

Dependent variable: ES

\begin{tabular}{cccc}
\hline \hline Excluded & Chi-sq & df & Prob. \\
\hline \hline RE & 12.65504 & 2 & 0.0018 \\
\hline \hline All & 12.65504 & 2 & 0.0018 \\
\hline \hline
\end{tabular}

Figure 2. VAR Granger causality test.

technical product structure, while the Sino-US export trade technology product structure is not the Granger reason of Sino-US bilateral real exchange rate. This demonstrates that the change of real exchange rate can explain the change of China's export Trade product technology structure to America. 


\subsection{The Analysis of Impulse Response}

In the analysis of VAR model, we usually do not analyze the influence of the change of one variable to other variables, but the influence of the endogenous variable on the other endogenous variables in the system, which is the analysis method of impulse response. In this part, the impulse response function is analyzed based on the VAR model set before, the specific pulse response diagram is shown in Figure 3 and Figure 4.

According to Figure 3, the impulse response function diagram of RE is obtained, and its hysteresis pulse effect is shown in the above figure. As can be seen from the figure, the real exchange rate of RMB against the United States dollar can affect China's export trade product structure to the US (proportion of medium and high tech exports to all export amounts to the United States, ES). After giving a positive impact to the bilateral real exchange rate, China has a negative response to the U.S. export-trade product structure in the first phase, and the

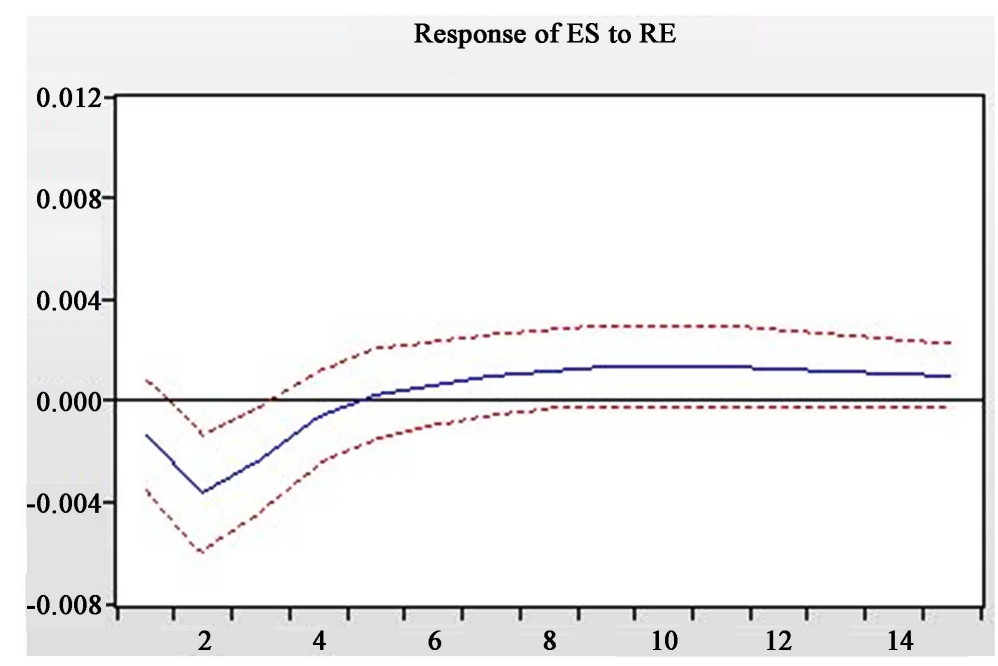

Figure 3. Response of ES to RE.

Response of RE to ES

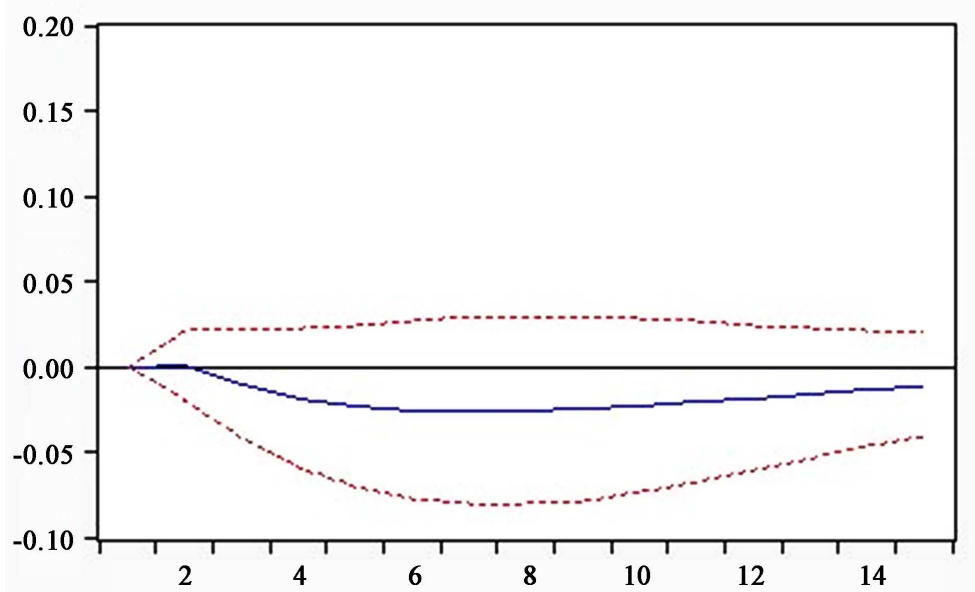

Figure 4. Response of RE to ES. 
second phase has the biggest negative response, for -0.004019 . The negative response showed a gradual downward trend, and at the fifth phase shifted to a positive response of 0.000181 . Subsequently, the response gradually expanded, at the 10th phase, it reached the maximum, 0.001792. Finally, this positive response tends to be 0 . In terms of impulse response, a positive impact on the real exchange rate of RMB against the dollar will have a negative effect on China-US export trade technology product structure, but the long-term effect is positive and the overall response is positive. This shows that the real appreciation of the dollar (real exchange rate depreciation), in the short term, will inhibit the improvement of China-US export trade technology product structure (the increase of the export ratio of medium and high technology products), and promote the improvement of the structure of China-US export trade technology products in the later period. Therefore, from the current background of RMB appreciation, the appreciation of RMB real exchange rate will promote the improvement of China-US export trade technology product structure (the ratio of medium and high technology export products) in the short term, which is the largest in the second phase, then the improvement effect is gradually reduced and the latter is negative. In the long run, the appreciation of $\mathrm{RMB}$ real exchange rate is unfavorable to the improvement of China-US export trade technology product structure (ratio of medium and high technology export products).

It can be seen from Figure 4 that when the technical structure of export trade products suffer from a positive impact, it will not immediately impact on the real exchange rate of the renminbi against the dollar. The effect starts from the second phase of a positive effect, but this effect is small, only for 0.000250. This response transfers to negative later, with the 7 th phase reaching its maximum of 0.026621 . Then the negative response gradually decreased, tending to 0 , and the overall performance was negative. Whether in the short or long term, the positive impact of China-US export trade technology product structure will have a big negative impact on the real exchange rate between China and US, which gradually expands in the short term and gradually tends to be 0 . But overall, this negative effect is persistent and intense. This shows that the improvement of China-US export trade product technology structure (the ratio of medium and high technology export products) will have an impact on the real exchange rate between China and the United States in the short and long term, and promote the real exchange rate depreciation (RMB real exchange rate appreciation).

\subsection{The Analysis of Variance Decomposition}

The impulse response analysis reveals the influence of an endogenous variable in an economic system on other endogenous variables and its influence path after suffering from an external shock. Instead, the variance decomposition method is to analyze the contribution of each structural impact to the variation of internal variables (generally measured by variance), and then to evaluate the importance 
of structural impact in the model. Therefore, the variance decomposition of the variables produced in the system can be decomposed by variance, we can analyze the relative importance of each random perturbation which affects the variables in the model. The detailed variance decomposition diagram is shown in Figure 5 and Figure 6.

From the variance decomposition diagram Figure 5, we can see that the real exchange rate between China and America has a great contribution to the structure of China-US export-trade technology products, which is consistent with the pulse response of bilateral real exchange rate.

From the variance decomposition diagram Figure 6, we can see that in the short term, the contribution rate of China-US export trade technology product structure to the bilateral real exchange rate is very small, which is consistent with the pulse response function. As time goes on, the contribution rate increases gradually, but the contribution rate is always small.

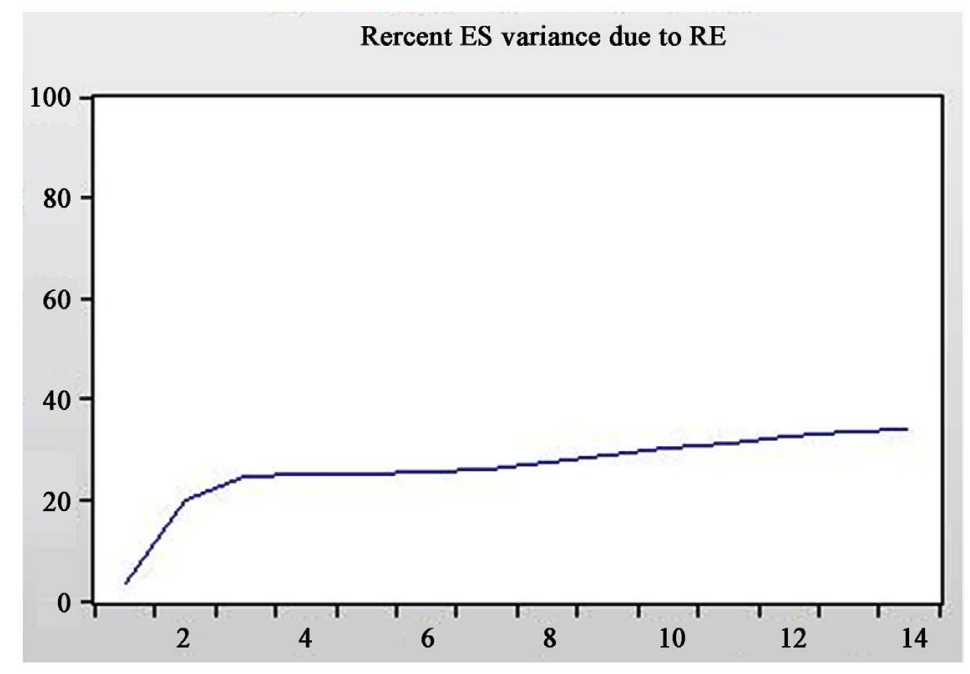

Figure 5. Percent ES variance due to RE.

Rercent RE variance due to ES

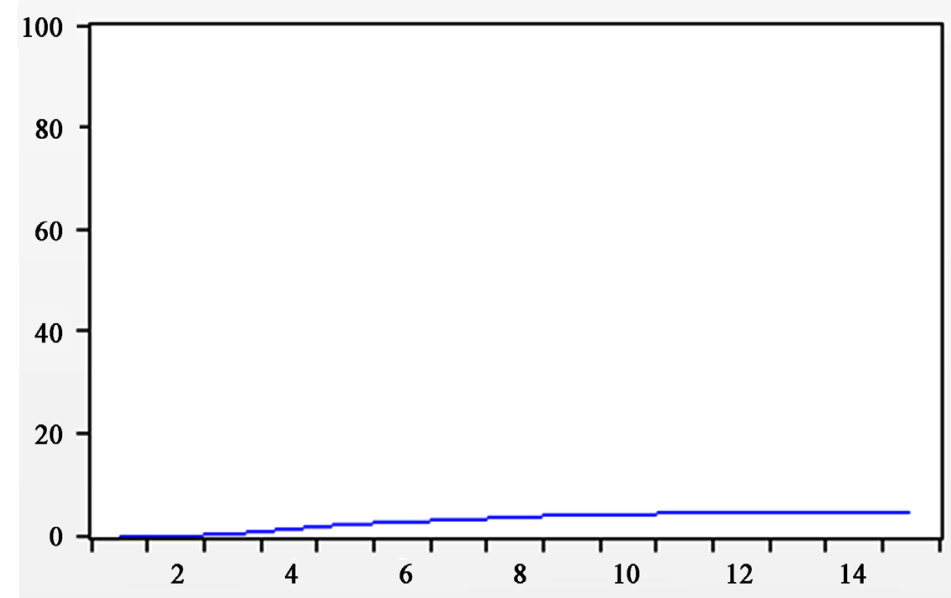

Figure 6. Percent RE variance due to ES. 


\section{Conclusions}

This paper studies the relationship between the real exchange rate of RMB against the United States dollar and China's export trade product structure on the basis of HS classification. Combining theory with practice, and based on the quarterly data of Sino-US bilateral real exchange rate fluctuation and Sino-US export trade technology product structure since 2005, the effect of bilateral real exchange rate fluctuation on the structure of Sino-US bilateral export trade is analyzed by using the vector autoregressive model, and the following main conclusions are obtained:

Firstly, the Granger causality test of endogenous variables in VAR model shows that the real exchange rate between China and America is the Granger reason of China-US export trade technology product structure. The Chinese and American Export trade technology product structure is not the Granger reason of Sino-US bilateral real exchange rate. It shows that the real exchange rate between China and America will have an impact on the structure of China-US export trade technology products.

Secondly, the analysis of impulse response function based on VAR model shows the effect of bilateral real effective exchange rate on the structure of China-US export trade technology products. The real effective exchange rate between China and America can be divided into two parts in the process of export trade technology product structure. The first part is the negative impact of one to four periods, the Sino-US bilateral real exchange rate, after suffering from a positive impact (the devaluation of the renminbi) in the first phase, will have a negative effect on Sino-US Export trade technology product structure, and this negative effect reaches to the largest in the second phase, and then continues to reduce. In the fifth phase, the positive effect of the second part begins to occur, and becomes the largest in the tenth phase, then gradually reduces to zero, but the overall effect is positive. Therefore, in the short term, the depreciation of the real exchange rate (appreciation) of the renminbi is not conducive (conducive) to the improvement of China-US bilateral export trade product structure. However, in the long run, the depreciation of RMB real exchange rate (revaluation) is beneficial (unbeneficial) to the improvement of China-US bilateral export trade product structure, but this influence of improvement reduces gradually. Overall, the appreciation of Sino-US bilateral real exchange rate is in favor of promoting the optimization of China-US export trade technology product structure.

Finally, from the variance decomposition of VAR model, the Sino-US bilateral real exchange rate has contributed greatly to the change of China-US export trade technology product structure, which has a tendency of increasing with time.

Although China's exports of High-tech products to the United States are numerous, one big reason is that developed countries outsource the final assembly of High-technology products to low-wage developing countries, and these High-technology products are "statistical hallucinations" for these developing 
countries. Therefore, the technical structure of Sino-US export trade containing the processing trade cannot truly reflect the technical structure of China's exports to the US. And the calculated technical structure of Sino-US export trade may be exaggerated, which cannot precisely reflect the changes in the technical structure of trade products, thus the relationship between the exchange rate and the technical structure of Sino-US export may not be true. Therefore, for the future research, the general trade products and processing trade products in the technical structure of Sino-US trade products may be studied precisely.

\section{References}

[1] Sanjaya, L. (2000) The Technological Structure and Performance of Developing Country Manufactured Exports: 1985-98. Oxford Development Studies, 28, 337-369. https://doi.org/10.1080/713688318

[2] Eichengreen, B.J. (1983) Effective Protection and Exchange-Rate Determination. Journal of International Money \& Finance, 2, 1-15. https://doi.org/10.1016/0261-5606(83)90002-5

[3] Capel, J. (1994) Exchange Rate Effects on a Firm's Output Composition. De Economist, 142, 475-496. https://doi.org/10.1007/BF01384467

[4] Obstfeld, M. and Rogoff, K.S. (1996) Foundations of International Macroeconomics. The MIT Press, Cambridge, Mass.

[5] Breuer, J.B. and Clements, L.A. (2003) The Commodity Composition of US-Japanese Trade and the Yen/Dollar Real Exchange Rate. Japan \& the World Economy, 15, 307-330. https://doi.org/10.1016/S0922-1425(02)00052-X

[6] Bahmani-Oskooee, M. and Hegerty, S.W. (2009) The Japanese-U.S. Trade Balance and the Yen: Evidence from Industry Dataz. Japan \& the World Economy, 21, 161-171. https://doi.org/10.1016/j.japwor.2008.02.001

[7] Cimoli, M., Fleitas, S. and Porcile, G. (2013) Technological Intensity of the Export Structure and the Real Exchange Rate. Economics of Innovation \& New Technology, 22, 353-372. https://doi.org/10.1080/10438599.2012.748504

[8] Zeng, Z. and Zhang, Y.B. (2007) Appreciation of RMB Real Exchange Rate and Adjustment of Chinese Export Trade Product Structure. World Economy, 5, 16-24.

[9] Wang, Y.W. (2009) The Effect of RMB Real Effective Exchange Rate and Its Fluctuation on China's Export Structure: An Empirical Study Based on ARDL-ECM Model. Quantitative Economic and Techno-Economic Research, 6, 53-63.

[10] Jin, G.H. (2010) Export Trade Structure Effect of RMB Exchange Rate Change. Zhejiang University, Hangzhou.

[11] Xiao, Q.X. and Liao, W.X. (2012) RMB Exchange Rate, Export Trade Structure and Sino-US Trade Balance: An Empirical Analysis Based on SITC Standard Industry Data. International Economic and Trade Exploration, 12, 60-72.

[12] Yu, J.J. and Lin, L. (2013) The Trade Difference of RMB Exchange Rate Incomplete Transmission: An Analysis of the Introduction of the Value of Trading. Contemporary Finance, 2, 87-97.

[13] Zhang, H.Q. (2015) RMB Appreciation, Commodity Heterogeneity and Export Restructuring. International Trade Issues, 2, 155-167.

[14] Ma, D. and Xu, S.Q. (2005) China's Trade Balance, Trade Structure and Real Effective Exchange Rate of RMB. Quantitative Economic and Techno-Economic Research, 6, 23-32. 
[15] OuYang, M. and Wang, S.P. (2005) An Empirical Study on the Relationship between Exchange Rate and China's Foreign Exports. International Trade Issues, 9, 115-118.

[16] Deng, S.L. and Wen, Y.Z. (2008) The Influence of RMB Exchange Rate Fluctuation on China's Import and Export Trade Structure. International Trade, 9, 26-31.

[17] Huang, W.Y. and Wang, W.G. (2010) RMB Exchange Rate and Sino-US Trade Imbalance: An Empirical Study Based on HS Classification Products. Quantitative Economic and Techno-Economic Research, 7, 76-90.

[18] Li, H.B., Ma, H., Xiong, Y.Y. and Xu, Y. (2011) The Impact of RMB Exchange Rate on Enterprises Import and Export Trade: An Empirical Study from Chinese Enterprises. Financial Research, 2, 1-16.

[19] Deng, X.H. and Li, Z.F. (2014) The Influence of Exchange Rate Fluctuation on China's Commodity Trade Structure. Quantitative Economic and Techno-Economic Research, 8, 56-71. 